\title{
CARDIAC ARREST CAUSED BY RAPID ELIMINATION OF NITROUS OXIDE FROM CEREBRAL VENTRICLES AFTER ENCEPHALOGRAPHY
}

\author{
Risto Collan, M.D., and Mattr Invanainen, M.D."
}

\begin{abstract}
DeSPITE REFINED TECHNIQUES, there still remains a problem of morbidity and even mortality after encephalography performed under general anaesthesia. ${ }^{1-3}$ It has been stressed recently that nitrous oxide rather than air should be used as a contrast medium during gas encephalography performed under nitrous oxide anaesthesia. ${ }^{2}$ The high solubility of nitrous oxide leads to a rapid elimination of the contrast gas. That this might be disadvantageous in certain circumstances seems not to have been given due consideration. Cardiovascular collapse occurring immediately after gas encephalography draws attention to a previously unnoticed danger connected with the use of nitrous oxide as contrast medium.
\end{abstract}

\section{CASE Report}

A 15-year-old male patient was admitted for gas encephalography, the indications being epilepsy and cerebral palsy (tetraplegia) of unknown origin. The boy was severely retarded (mental age eight months). He was taking phenytoin 200 mg per day at the time of the investigation. Chest X-ray and EcG revealed nothing abnormal. Haemoglobin was $14.1 \mathrm{gm} / 100 \mathrm{ml}$. His weight was $36 \mathrm{~kg}$. He was premedicated with atropine sulfate $0.5 \mathrm{mg}$ and sodium pentobarbital $150 \mathrm{mg}$ i.m. 50 minutes before the anaesthesia. Anaesthesia was induced with propanidid (Epontol ${ }^{\oplus}$, Bayer) $300 \mathrm{mg}$ i.v. After intubation under succinylcholine (30 mg), relaxation anaesthesia was maintained with a mixture of halothane (1-0.6 per cent) using a Fluotec Mark II vaporizer and nitrous oxide and oxygen (4L/4L). The patient was breathing spontaneously throughout the procedure through a Magill's attachment, the respiratory rate varying between 16 and 18 per minute. The arterial systolic blood pressure, which was $95 \mathrm{~mm} \mathrm{Hg}$ before induction, remained stable at $90 \mathrm{~mm} \mathrm{Hg}$ during the time patient was kept sitting. During the investigation, performed by the fractional technique, ${ }^{4}$ a total of $64 \mathrm{ml}$ of anaesthetic gas mixture was injected into the subarachnoid space through a lumbar needle and about $60 \mathrm{ml}$ of cerebrospinal fluid (CSF) was removed.

At the end of the procedure, with the patient in the prone position, $4.9 \mathrm{mg}$ thiethylperazine (Torecan ${ }^{\circledR}$, Sandoz) was given intramuscularly. A little later halothane administration was discontinued and atropine $0.2 \mathrm{mg}$ was given intravenously. The patient was turned in supine position after the filling of the left temporal horn, nitrous oxide was cut off, and pure oxygen with a flow of about 9 $\mathrm{L} / \mathrm{min}$ was given. For extubation under complete relaxation without laryngeal spasm $30 \mathrm{mg}$ of succinylcholine was given intravenously. Continuous palpation

'Fourth Department of Surgery and Department of Neurology, University of Helsinki, and Research Department of Rinnekoti Institution for the Mentally Retarded, Majalampi, Finland.

Can. Anaes. Soc. J., vol. 16, no. 6, November 1969 

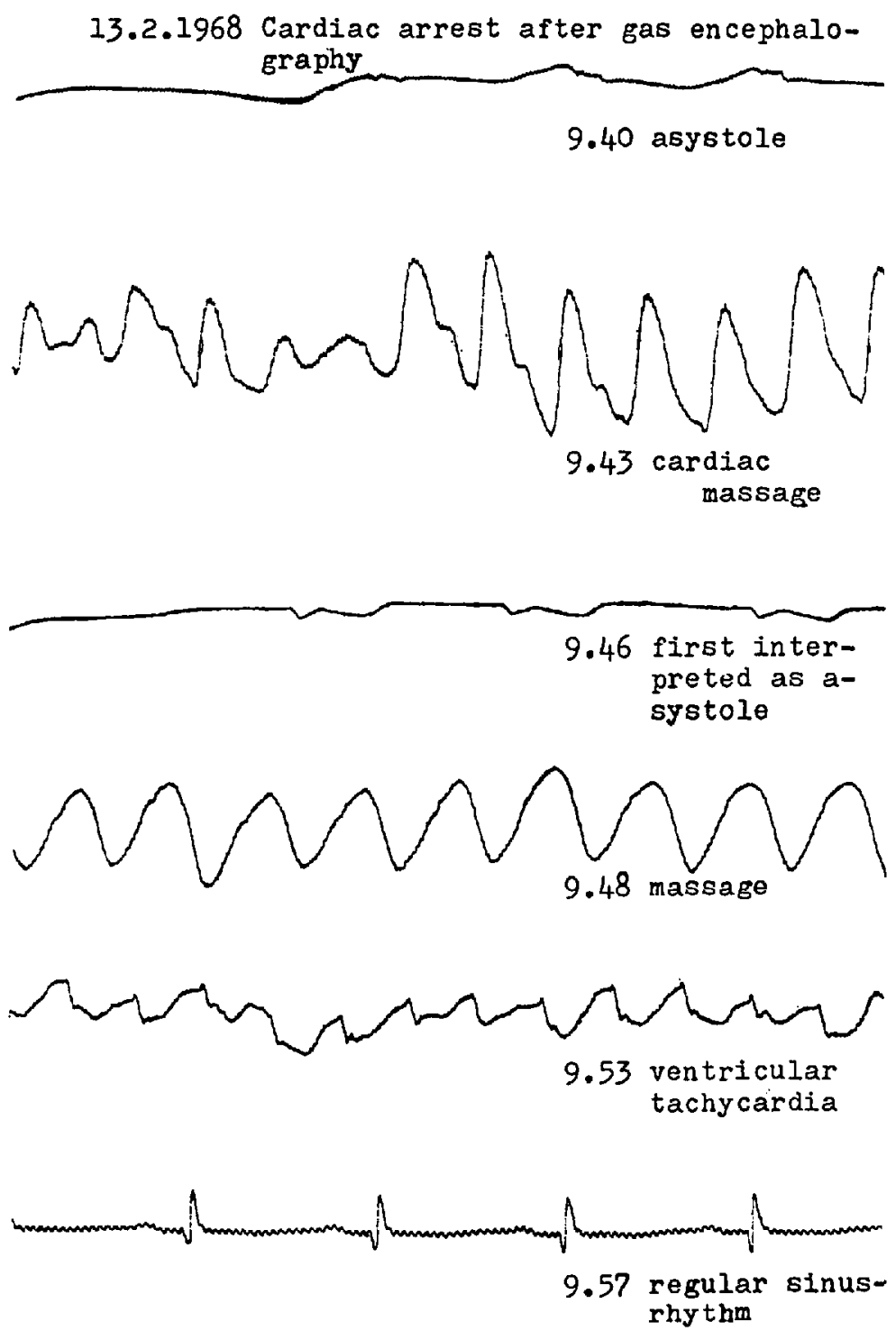

Ficure 1. ECc tracing showing different stages of electrical cardiac activity during resuscitation. Lead 1. For the first five tracings the paper speed was $2.5 \mathrm{~cm} / \mathrm{sec}$. For the sixth tracing it was $5 \mathrm{~cm} / \mathrm{sec}$.

of the pulse did not reveal any bradycardia or arrythmia following succinylcholine. After moderate muscle fibrillations extubation was performed, preceded by manual ventilation. Immediately before extubation the pulse was regular. One minute after extubation deep spontaneous breathing started but the pulse was found to be absent. Suddenly the patient appeared very pale in contrast to the good colour present throughout the procedure. Cardiac auscultation revealed a regular rhythm, the frequency being over $100 / \mathrm{min}$. No murmur could be heard. Eighttenths of a milligram of metaraminol (Aramine ${ }^{\circledR}$, Merck, Sharp, Dohme) was 


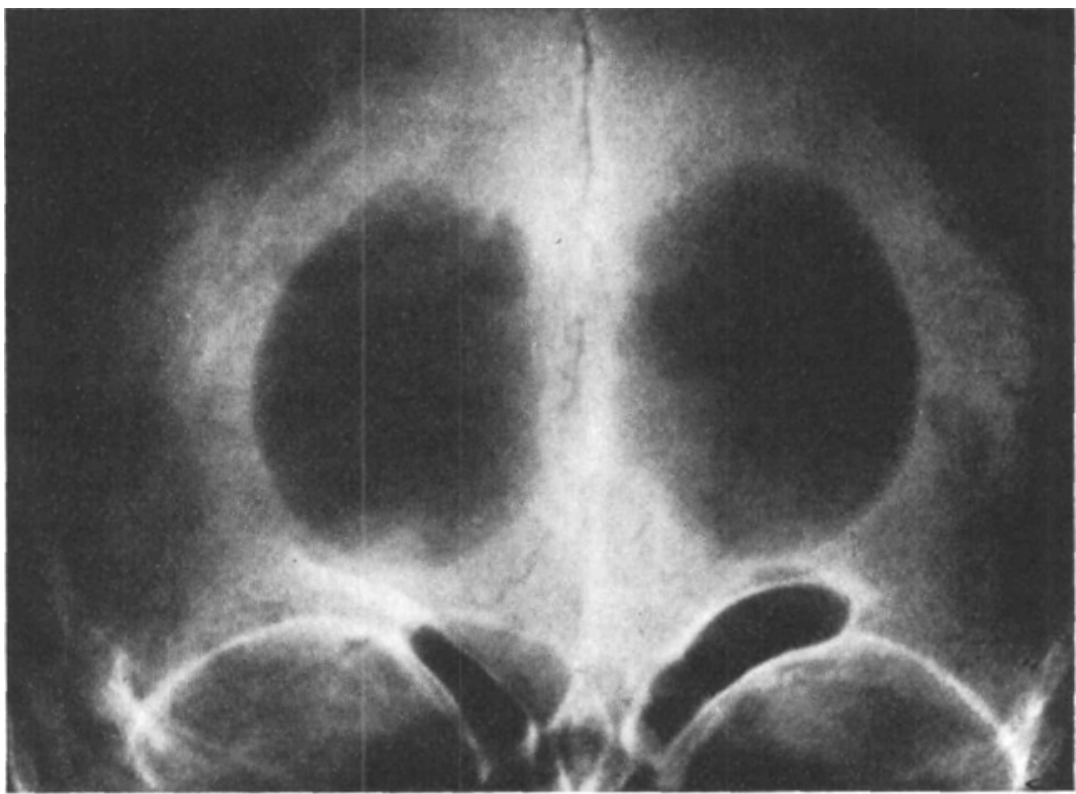

Figure 2. Gas encephalogram, anteroposterior projection, the patient supine. Both frontal horns are greatly dilated.

given intravenously. The regular deep breathing ended in a forced and prolonged expiration, so strong that the abdominal muscles were seen to be contracted for several minutes. Manual ventilation was immediately started again with a mask and it was very easy despite the contracture of the abdominal muscles. After two blows on the precordium, external cardiac massage was started. Eight minutes after the respiratory arrest ECG revealed asystole (Fig. 1). Over the 20 minutes following the arrest the patient was given $145 \mathrm{mEq}$ sodium bicarbonate, epinephrine $0.5 \mathrm{mg}$ i.v. twice and atropine $0.8 \mathrm{mg}$. At the end of this period the patient started to resist manual ventilation, and ECG showed ventricular tachycardia. Five millilitres of 10 per cent $\mathrm{CaCl}_{2}$ solution were given i.v. because a palpable pulse was still absent. Two minutes later the patient's face suddenly became flushed, deep spontaneous breathing started, and the ECG showed a regular sinus rhythm. Blood pressure was $105 \mathrm{~mm} \mathrm{Hg}$. Thirty-five minutes after the incident the patient reacted to a pinch on the ear. During the following eight hours, $200 \mathrm{ml}$ of 20 per cent mannitol was slowly administered. One hour after the arrest a blood sample was obtained which showed a $\mathrm{pH}$ of 7.80 and an alkaline reserve of 85 per cent. Urine voided five hours later was red in colour. The haemacombistix (Ames Company) test showed glucose + , protein +++ , blood ++++ .

In the encephalogram internal hydrocephalus and a weakly developed brain stem were observed (Fig. 2).

\section{Discussion}

The diagnosis of cardiac arrest was based on the absence of a palpable pulse and on dilating pupils as a sign of inadequate cerebral circulation. The promptly 
instituted external cardiac massage restored the cerebral circulation and, together with the other steps taken, overcame the cardiovascular collapse.

Because of its greater solubility in the tissues, there is a rapid influx of nitrous oxide into the cerebral ventricles during gas encephalography if air is used as contrast medium. ${ }^{2}$ Our practice in over 300 gas encephalographies performed since January 1967 has been to inject the same gas mixture as the patient is breathing. In that way we obtain almost the same partial pressure of nitrous oxide in the tissues and in the intraventricular gas. This prevents the fluctuation of gas volume during the procedure, which in case of incomplete filling might easily result in failure because of diminution of the gas volume if the investigation for some reason is unduly prolonged. When the anaesthetic gas mixture is withdrawn and the patient starts to breath oxygen or air, there is a rapid disappearance of nitrous oxide from the ventricles, causing a rapid decrease of cerebrospinal pressure. ${ }^{2}$ This occurs in as little as three or four minutes. Considering this and the inevitable leakage around the lumbar needle, ${ }^{5}$ we must agree that the rapid elimination of nitrous oxide may easily cause a deleterious decrease in the CSF pressure after gas encephalography. That rapid decompression of dilated ventricles may cause cardiovascular collapse has recently been reported. ${ }^{6}$

The forced and sustained expiration noticed in the beginning of the collapse was apparently due to stimulation of the expiratory centre and confirms that something happened inside the cranium. It was probably due to stretching of the weakly developed brain stem caused by the ventricular decompression, or it may have been reflex in origin.

Venous air embolism is a recognized cause of death during gas encephalography. Cardiac auscultation ruled out this possibility in the present case. At the first signs of cardiovascular collapse, weak heart sounds were heard but definitely no murmur.

Twelve minutes before the incident, $4.9 \mathrm{mg}$ thiethylperazine was administered intramuscularly to prevent vomiting after the examination. It is unlikely that such a small dose could have caused the collapse. Others have used much higher doses of this drug (up to $13 \mathrm{mg}$ ) to prevent postoperative vomiting without any ill effects on cardiovascular function..$^{7,8}$

A too rapid decrease in an elevated $\mathrm{PCO}_{2}$ may cause a fall in arterial blood pressure. This is mainly connected with the chronically elevated values of $\mathrm{PCO}_{2}$, as in severe emphysema. This patient's spontaneous breathing was regular and deep enough not to cause concern during the anaesthesia. Occasional deep breaths were administered manually during the anaesthesia, and the lungs were auscultated after intubation to secure the right position of the tube, which was firmly taped in place. With the anaesthetic technique used a slight increase in the $\mathrm{PCO}_{2}$ usually develops but when the patient wakes up it quickly returns to a normal level without adverse effects on the circulation. The dose of sodium bicarbonate seems, in retrospect, to have been too high. It may however, have helped in the rapid success of the resuscitation. A high $\mathrm{PCO}_{2}$ is the most powerful stimulus for increasing cerebral blood flow and, of course, for elevating the intracranial pressure.

Other explanations in this case seem to be far more unlikely. A well-known 
fact is that succinylcholine, if given a second time during anaesthesia, often causes bradycardia and even cardiac arrest. According to Droh, ${ }^{9}$ this effect is probably central. It is prevented by atropine. Atropine was also given in this case in the latter part of the anaesthesia to prevent bradycardia. The occurrence of a vagal reflex, which might have been caused by laryngeal irritation during extubation, appears unlikely, because of the administration of atropine preceding extubation and the observed rapid cardiac action at the first signs of cardiovascular collapse.

The red colour of the urine and the positive haemacombistix reaction for protein and blood could be explained by the presence of red cells, haemoglobin or myoglobin. Which of these three was the cause can only be surmised. Myoglobinuria does sometimes occur after intermittent administration of succinylcholine during halothane anaesthesia. ${ }^{\text {t0 }}$ Two doses given to this patient might well have caused myoglobinuria. The high osmolality of the 20 per cent mannitol solution may also have caused destruction of red cells, causing haemoglobinuria.

Of the possible explanations considered, the intracranial decompression theory seems to us the most plausible. This phenomenon should be kept in mind when performing gas encephalography with nitrous oxide or a mixture containing nitrous oxide as contrast medium under general anaesthesia, especially in patients with hydrocephalus.

In order to prevent this accident in patients with hydrocephalus, one should omit nitrous oxide from the anaesthetic gas mixture and use air or oxygen instead as a contrast medium. The treatment of an incident like this is a more difficult problem. The decompression occurs at the end of the procedure after the lumbar needle has been withdrawn. An immediate injection of saline into the subarachnoid space, which would be the most reasonable thing, is thus impossible. All other measures that raise intracranial pressure are recommended; for example, Queckenstedt's manoeuvre.

\section{SUMMARY}

A case of cardiovascular collapse after gas encephalography is presented. It draws attention to a previously unreported danger connected with the use of nitrous oxide or a mixture of nitrous oxide and oxygen as a contrast medium in encephalography. The rapid elimination of nitrous oxide may lead to a deleterious decrease in cerebrospinal pressure in patients with large cerebral ventricles.

\section{RÉSUMÉ}

Nous présentons un cas de défaillance cardiovasculaire après encéphalographie gazeuse. Cela démontre un danger non signalé jusqu'ici, dû à l'usage de l'oxygène et le protoxyde d'azote comme agent contrastant en encéphalographie. L'élimination rapide du protoxyde d'azote peut conduire à une réduction défavorable de la pression cérébrospinale chez les patients avec gros ventricules cérébraux.

\section{REFERENCES}

1. Rovira, M. \& Barluenca, S. A propos de deux cas de complications de l'encephalographie fractionnée chez l'enfant. J. Belge Radiol. 50; 158 (1967). 
2. Samman, Lawrence J. \& Eger, Edmond I., II. Change in Cerebrospinal Fluid Pressure during Pneumoencephalography under Nitrous Oxide Anesthesia. Anesthesiology. 26: 67 (1965).

3. SpITz, E. B.; Adamson, W. C.; \& NoE, W. L., JR. Criteria for Pneumoencephalography in Differential Diagnostic Study of Mental Subnormality. Am. J. Ment. Defic. 66: 561 (1962).

4. LINDGREN, E. Röntgenologie. In: Handbuch der Neurochirurgie. Ed. H. Olivecrona and W. Tonnis. Berlin: Springer-Verlag (1954).

5. LuNDBERG, N. \& West, K. A. Leakage as a Source of Error in Measurement of the Cerebrospinal Fluid Pressure by Lumbar Puncture. Acta neurol. scandinav. 41, Suppl. 13: 115 (1965).

6. Bafl, C. P. \& Wadwa, Shanta. Cardiovascular Collapse after Rapid Ventricular Decompression in Hydrocephalus: Case Report. Brit. J. Anaesth. 39: 657 (1967).

7. BAUER, AKE. Antiemetic Effect of Thiethylperazine (Torecan(B) in Connection with Surgery. Acta chir. scandinav. 132: 493 (1966).

8. LuTz, Horst. Zur Prophylaxe von Nausea und Erbrechen in der fruhen postoperativen Phase. Der Chirurg. 37: 27 (1966).

9. Dяон, R. Die Wirkung von Acetylcholin auf das isolierte Herz: Beitrag zur Aufklärung des Wirkungsmechanismus von Succinylbischolin am menschlichen Herzen. Anaesthesist. 17: 54 (1968).

10. Amaksinen, M. M. \& Tammisto, T. Myoglobinuria after Routine Intermittent Administration of Succinylcholine during Halothane Anesthesia. Clin. Pharmacol. 7: 83 (1966). 